\title{
The Impact of Abusive Supervision on Job Insecurity: A Moderated Mediation Model
}

\author{
Junjie Wang \\ Jinan University, Guangzhou, China \\ Email: wjj_gin@163.com
}

How to cite this paper: Wang, J. J. (2020). The Impact of Abusive Supervision on Job Insecurity: A Moderated Mediation Model. Open Journal of Social Sciences, 8, 200-207. https://doi.org/10.4236/jss.2020.86016

Received: May 21, 2020

Accepted: June 9, 2020

Published: June 12, 2020

Copyright $\odot 2020$ by author(s) and Scientific Research Publishing Inc. This work is licensed under the Creative Commons Attribution International License (CC BY 4.0).

http://creativecommons.org/licenses/by/4.0/

\begin{abstract}
Abusive supervision is closely related to the negative psychological reaction of employees. This paper mainly discusses the influence mechanism of the abusive supervision on the job insecurity. A moderated mediation model is put forward. Study used questionnaire to investigate the enterprise staff. The results showed: 1) Abusive supervision has a direct impact on job insecurity, and also has indirect impact on job insecurity through the LMX; 2) The power distance has a moderated effect on the mediated role of LMX. To be specific, the impact of the Abusive supervision on job insecurity through the LMX decreased with the increase of the power distance. Therefore, the influence mechanism of abusive supervision on job insecurity is a moderated mediation model.
\end{abstract}

\section{Keywords}

Abusive Supervision, Job Insecurity, LMX, Power Distance

\section{Introduction}

Since the 1980s, a series of studies on positive leadership behavior have emerged, including Charismatic Leadership (House, 1976), Transformative Leadership (Bass, 1990), and Visionary Leadership (Nanus, 1992). In real life, leadership behavior is not always positive, and leaders may be selfish and grumpy. Abusive supervision is a typical representative of negative leadership behaviors. Abusive supervision is defined as the level of perceived verbal or non-verbal hostile behaviors perpetually demonstrated by employees, excluding physical contact (Tepper, 2000, 2007). Studies have shown that abusive supervision is closely related to many negative psychological reactions of employees, including depression, anxiety, emotional exhaustion, physical illness and job dissatisfaction (Lin, Wang, \& Chen, 2013). Based on previous studies, our study chose negative psy- 
chological reactions-Job insecurity as a dependent variable, to explore the mechanism between abusive supervision and job insecurity. At present, the definition of job insecurity has not been agreed in the theoretical world. The most recognized and cited by scholars is the definition of job insecurity in Greenhalg and Rosenblatt's pioneering research, that is, "employees are in a threatening work environment, a sense of powerlessness to maintain the continuity of work" (Greenhalgh \& Rosenblatt, 1984). In our study, job insecurity is regarded as a subjective psychological phenomenon, which refers to an employee's negative expectation of job loss in a bad work situation. In other words, it's a negative cognitive interpretation of environmental variables. Recently, researchers have focused more on the mechanism between abusive supervision and employees' negative psychological reactions. Under this trend, this study first introduced the relationship between abusive supervision and employees' job insecurity. Leader-member exchange (LMX) is investigated, and its intermediary effect is examined. LMX refers to the quality of the relationship between leaders and employees, which assumes that leaders tend to form different connections with different subordinates (Graen \& Uhl Bien, 1995). Abusive supervision would damage the quality of the relationship between leaders and subordinates, that is, low-level LMX, so that employees feel strong job insecurity.

Although we have assumed that abusive supervision can have an impact on job insecurity through LMX, it is undeniable that there will be individual differences in this mechanism of influence. Therefore, we introduce a second variable, the power distance, to examine its regulatory effect in the indirect path. For the first time, Hofstede (1980) extended the concept of power distance to the cross-cultural field, defining it as "the degree of individual acceptance of unfair power distribution in organizations". High-power distance-oriented employees are more likely to accept, obey and trust their leaders (Kirkman \& Lowe, 2009). In other words, they always maintain a belief that employees should not oppose their leaders, but should obey and accept their leaders' decisions. There are two reasons for choosing power distance as a moderating variable. First, many studies have shown that power distance is a very important cultural value orientation. Studies have shown that employees' cultural value orientation plays an important role in all aspects of their work performance (Gelfand, Erez, \& Aycan, 2007; Kirkman, Lowe, \& Gibson, 2006); Second, the essence of power distance is a subjective experience of employees themselves, which can affect employees' perception of undesirable objective situations (such as low-level LMX) and further affect employees' psychological reactions. By introducing two variables-LMX and power distance, the mechanism between abusive supervision affects job insecurity is revealed in more detail.

\section{Research Model}

\subsection{The Intermediary Role of Leadership-Member Exchange}

LMX theory indicates that leader and different employees will establish different relationship qualities. Leaders and employees decide and develop their exchange 
relationship through a role-making process, that is, they tend to base their expectations on a specific role to evaluate each other (Graen \& Cashman, 1975), employees expect leaders to understand and support their ideas, and both parties can communicate effectively. However, abusive supervision will make employees feel that their leaders cannot meet their expectations for leadership roles. Based on the social exchange theory, employees who feel the exploitation from the leader will take negative actions in return. In simple terms, abusive supervision damages the LMX.

When employees and their leaders are in a low-level LMX, it is difficult for them to get the attention of the leaders, and more importantly, they cannot obtain valuable resources from the leaders, which is likely to be a hindrance to have a good performance. In a highly competitive organization, performance is a quantified indicator of employees' abilities. Employees without better performance would lose assurance of continuity of work and create a sense of job insecurity.

Above all, a new intermediary model between abusive supervision and job insecurity has been generated; abusive supervision damages the quality of the relationship between leaders and employees, which in turn causes employees to feel job insecurity.

H1: Leader-member exchange has an intermediary effect on the relationship between abusive supervision and job insecurity, that is, abusive supervision affects job insecurity through leader-member exchange.

\subsection{The Moderation of Right Distance}

Although through theoretical analysis we infer that the low-level LMX between will cause employees to feel insecure at work, we cannot deny that there may be individual differences in this mechanism. Our study takes power distance as a moderating variable, which is a typical representative of cultural value orientation, to examine the moderating effect of power distance in the relationship between LMX and employees' job insecurity.

The analysis of the moderation effect of power distance can be based on the cognitive-evaluation theory put forward by Lazarus \& Folkman (1984). Cognitive-evaluation refers to "individuals assess whether a particular stimulus in the environment is related to their own interests, and if so, in what way to contact" (Folkman, Lazarus, Dunkel-Schellter, DeLongis, \& Gruen, 1986; Lian, Ferris, \& Brown, 2012). The core point of the cognitive-evaluation theory is that the evaluation made by individuals affects the pressure they feel when responding to environmental stimuli. The degree of tension an individual produces due to stressors depends on how they interpret the stressors. Once the individual evaluates the stimulus as negative and will have a greater degree of negative impact on himself, the individual will have a certain psychological and behavioral response. In addition, cognitive evaluation theory believes that some individual characteristics are important factors that affect evaluation, such as individual power distance. Power distance shows the individual's perception of the rights and status 
in the organization. The level of employee power distance can influence individual evaluation of an event, shaping the understanding of the event, and laying the foundation for the assessment of consequences (Lazarus \& Folkman, 1984). When employees maintain a high-level LMX, regardless of whether the employee's power distance is high or low, employees tend to produce less negative emotions and behavioral responses; while when employees and their leaders establish a low-level LMX, the employee's power distance will greatly affect the employee's evaluation of this relationship. Individuals with high power distances have a higher degree of recognition of the hierarchical system in the organization. They consider themselves to be lower than their leaders in the organization, and regard the low-level LMX as it should be. On the contrary, individuals with low power distance seek equal status in the organization, and the low-level LMX exacerbates the inequality in the relationship between the two parties. That is, employees of low power distance have great conflict with their own beliefs. Therefore, they will evaluate this low-level LMX as a high threat during their cognitive evaluation process, which will seriously damage their work stability and continuity.

$\mathrm{H} 2$ : The power distance has a moderating effect on the intermediary role of the leader-member exchange. The power distance regulates the second half of the intermediary process. Specifically, the influence of the abusive supervision on job insecurity through LMX decreases as the power distance increases.

\section{Method}

\subsection{Subject}

A total of 550 questionnaires were distributed in our study, and 464 valid questionnaires were recovered. Among them, 23 were male and 441 were female; 344 were married and 120 were unmarried. There are 125 people with high school education or below, 271 with junior college degree, and 65 with undergraduate education; 62 people under 25, 283 with 26 - 30 years old, and 118 with 31 - 40 years old. There are 54 people with a working period of less than 3 years, 204 with 4 - 6 years, and 202 with more than 7 years.

\subsection{Tools}

\subsubsection{Abusive Supervision Scale}

We chose the Abusive Supervision Scale prepared by Tepper (2000) and revised by Zhu Ying (2012), it contains 10 items. The scale covers two dimensions, named mocking depreciation and neglecting concealment. The mocking depreciation dimension contains 6 items, such as "My boss is rude to me", the internal consistency coefficient is 0.991 ; the neglecting hidden dimension contains 4 items, Such as "Despite my hard work, my boss will not praise", the internal consistency coefficient is 0.914 . The scale uses a five-point scoring scale, ranging from "never" to "Always", scoring 1 to 5 points. The internal consistency coefficient of the total scale is 0.925 . 


\subsubsection{Leadership-Member Exchange Scale}

Based on Scandura and Graen (1984), the LMX-7 scale revised by Hui et al. (1999). Which contains 7 items, such as "I and my boss have a good working relationship." The scale adopts five-point scoring, and its internal consistency coefficient is 0.86 .

\subsubsection{Power Distance Scale}

Using the individual rights distance scale compiled by Dorfman and Howell (1988), it contains 6 items, such as "Leaders need to be consulted when making decisions". The scale uses 5 points for scoring, ranging from "completely disagree" to "completely agree", The internal consistency coefficient is 0.70 ;

\subsubsection{Job Insecurity Scale}

The Job Insecurity Scale (JIM) compiled by O'Neill and Sevastos (2013), which contains a total of 18 items. The scale contains four dimensions. Among them, the job loss insecurity (JLI) contains 6 items (T1-T6), such as "No matter how hard I work, I cannot guarantee the continuity of work", the internal consistency factor is 0.901; OSI contains 3 items (T7-T9), such as "Senior managers really work hard to run the company and make it successful", using reverse scoring, the internal consistency coefficient is 0.868 ; Job change insecurity (JCI) includes 6 items (T10-T15), such as "my work compensation may be reduced", the internal consistency coefficient is 0.904 ; marginal insecurity (MI) contains 3 items (T16-T18), such as "I am often excluded from discussions or meetings that can affect me", the internal consistency factor is 0.882 . The scale adopts five-point scoring, ranging from "strongly disagree" to "strongly agree".

\section{Result}

\subsection{Common Method Deviation}

In this study, the Harman single factor test method is used to test the systematic error caused by the common method deviation. The results showed that using exploratory factor analysis, a total of 7 factors were isolated. The overall variance explanation rate was $77.823 \%$, and the first common factor explained rate was $32.044 \%$. According to the research of Long Lirong and Zhou Hao (2004), there is no serious common method deviation in this study.

\subsection{Correlation Analysis}

Table 1 lists the mean, standard deviation and correlation matrix of the variables. Abusive supervision has a significant positive correlation with job insecurity $(r=0.229, p<0.01)$, and a significant negative correlation with the leader-member exchange $(r=-0.435, p<0.01)$. There is a significant negative correlation between leadership-member exchange and job insecurity $(r=-0.364, p<0.01)$.

\subsection{Intermediary Effect}

In the first step, regression analysis of job insecurity to abusive supervision found 
that $\beta=0.229, p<0.001$, there is a main effect. Abusive supervision significantly predicts job insecurity. The second step is to do a regression analysis of leadership-member exchange for abusive supervision and find that $\beta=-0.435, p<$ 0.001 , abusive supervision significantly predicts leadership-member exchange. In the third step, taking job insecurity as the dependent variable, the leadership-member exchange and abusive supervision are included in the equation at the same time. It is found that abusive supervision has no significant effect on job insecurity, $\beta=0.089, n s$., and leadership-Member exchange has a significant effect on job insecurity, $\beta=-0.324, p<0.001$. As shown in the review, Hypothesis 1 is supported, and the leader-member exchange plays an intermediary role in the impact of abusive supervision on job distress in Table 2.

\subsection{A Moderated Mediation Model}

First, standardize the independent and regulated variables. Model 14 was selected, 2000 tests were performed, and the confidence interval was $95 \%$. It was found that the leader-member exchange had a significant effect on job insecurity, $\beta=-0.324, p<0.001$. Abusive supervision and power distance have no significant effect on job insecurity, $p>0.05$. The interaction terms of power distance and leadership-member exchange significantly predict job insecurity, $\beta=$ $0.125, p<0.01$.

Further simple slope analysis found that for participants with high power distance orientation, the LMX cannot significantly predict job insecurity, $\beta=$ $-0.169, p>0.05$. For participants with low power distance orientation, LMX significantly predicted job insecurity, $\beta=-0.325, p<0.01$. Hypothesis 2 is supported in Figure 1. Power distance has a moderating effect on the intermediary

Table 1. Mean, standard deviation and correlation matrix $(\mathrm{N}=464)$.

\begin{tabular}{|c|c|c|c|c|c|c|}
\hline & $\mathrm{M}$ & $\mathrm{SD}$ & $\begin{array}{c}\text { Abusive } \\
\text { supervision }\end{array}$ & job insecurity & LMX & $\begin{array}{c}\text { Power } \\
\text { Distance }\end{array}$ \\
\hline Abusive supervision & 1.442 & 0.581 & & & & \\
\hline Job insecurity & 3.321 & 0.979 & $0.229^{\star *}$ & & & \\
\hline LMX & 3.9 & 0.673 & $-0.435^{\star *}$ & $-0.364^{\star *}$ & & \\
\hline Power Distance & 2.159 & 0.749 & $0.208^{\star *}$ & $0.135^{\star *}$ & $-0.246^{* *}$ & \\
\hline
\end{tabular}

${ }^{* *} p<0.001,{ }^{*} p<0.05$.

Table 2. Intermediary effect.

\begin{tabular}{|c|c|c|c|c|c|c|}
\hline & \multicolumn{2}{|c|}{ M1 } & \multicolumn{2}{|c|}{ M2 } & \multicolumn{2}{|c|}{ M3 } \\
\hline & $\beta$ & $\mathrm{t}$ & $\beta$ & $\mathrm{t}$ & $\beta$ & $\mathrm{t}$ \\
\hline Abusive supervision & 0.229 & $5.028^{* * *}$ & -0.435 & $-10.284^{\star * *}$ & 0.089 & 1.826 \\
\hline LMX & & & & & -0.324 & $-6.663^{* * *}$ \\
\hline $\mathrm{R}^{2}$ & \multicolumn{2}{|c|}{0.51} & \multicolumn{2}{|c|}{0.187} & \multicolumn{2}{|c|}{0.134} \\
\hline $\mathrm{F}$ & \multicolumn{2}{|c|}{$25.282^{\star \star \star *}$} & \multicolumn{2}{|c|}{$105.759^{\star * *}$} & \multicolumn{2}{|c|}{$36.018^{* * *}$} \\
\hline
\end{tabular}

${ }^{* * *} p<0.001,{ }^{* *} p<0.01,{ }^{*} p<0.05$. 


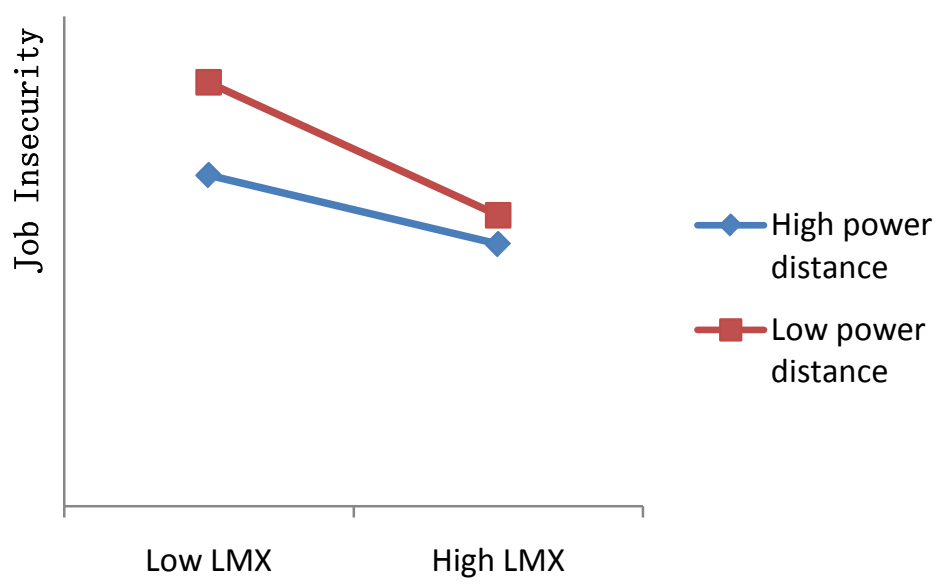

Figure 1. Simple slope analysis.

role of leader-member exchange. Power distance regulates the second half of the intermediary process.

\section{Conclusion}

This study proposes that there is an intermediary role of leadership-member exchange between abusive supervision and employees' job insecurity, and further reveals the mechanism of abusive supervision on employees' job insecurity. That is, abusive supervision affects the psychological reaction of employees by impairing the quality of the relationship between leaders and employees, resulting in a sense of job insecurity. And this influence mechanism is regulated by the power distance, and employees with different power distances will have different perceptions when faced with the low-quality relationship with the leader, which will lead to different degrees of job insecurity.

\section{Conflicts of Interest}

The author declares no conflicts of interest regarding the publication of this paper.

\section{References}

Bass, B. M. (1990). From Transactional to Transformational Leadership: Learning to Share the Vision. Organizational Dynamics, 18, 19-31. https://doi.org/10.1016/0090-2616(90)90061-S

Dorfman, P. W., \& Howell, J. P. (1988). Dimensions of National Culture and Effective Leadership Patterns: Hofstede Revisited. In R. N. Farmer, \& E. G. Goun (Eds.), Ad vances in International Comparative Management (Vol. 3, pp. 127-150). Greenwich, CT: JAI Press.

Folkman, S., Lazarus, R. S., Dunkelschetter, C., Delongis, A., \& Gruen, R. J. (1986). Dynamics of a Stressful Encounter: Cognitive Appraisal, Coping, and Encounter Outcomes. Journal of Personality \& Social Psychology, 50, 992-1003. https://doi.org/10.1037/0022-3514.50.5.992

Gelfand, M. J., Erez, M., \& Aycan, Z. (2007). Cross-Cultural Organizational Behavior. 
Annual Review of Psychology, 58, 479-514.

https://doi.org/10.1146/annurev.psych.58.110405.085559

Graen, G. B., \& Uhl-Bien, M. (1995). Relationship-Based Approach to Leadership: Development of Leader-Member Exchange (LMX) Theory of Leadership over 25 Years: Applying a Multi-Level Multi-Domain Perspective. Leadership Quarterly, 6, 219-247. https://doi.org/10.1016/1048-9843(95)90036-5

Graen, G., \& Cashman, J. F. (1975). A Role-Making Model of Leadership in Formal Organizations: A Developmental Approach. Kent, OH: Kent State University.

Greenhalgh, L., \& Rosenblatt, Z. (1984). Job Insecurity: Toward Conceptual Clarity. Academy of Management Review, 9, 438-448. https://doi.org/10.5465/amr.1984.4279673

Hofstede, G. (1980). Motivation, Leadership, and Organization: Do American Theories Apply Abroad? Organizational Dynamics, 9, 42-63. https://doi.org/10.1016/0090-2616(80)90013-3

House, R. J. (1976). A 1976 Theory of Charismatic Leadership. Working Paper Series 76-06. Bibliographies, 38.

Hui, C., Law, K. S., \& Chen, Z. X. (1999). A Structural Equation Model of the Effects of Negative Affectivity, Leader-Member Exchange, and Perceived Job Mobility on In-Role and Extra-Role Performance: A Chinese Case. Organizational Behavior \& Human Decision Processes, 77, 3-21. https://doi.org/10.1006/obhd.1998.2812

Kirkman, B. L., \& Lowe, K. B. (2009). Individual Power Distance Orientation and Follower Reactions to Transformational Leaders: A Cross-Level, Cross-Cultural Examination. Academy of Management Journal, 52, 744-764.

https://doi.org/10.5465/amj.2009.43669971

Kirkman, B. L., Lowe, K. B., \& Gibson, C. B. (2006). A Quarter Century of Culture's Consequences: A Review of Empirical Research Incorporating Hofstede's Cultural Values Framework. Journal of International Business Studies, 37, 285-320. https://doi.org/10.1057/palgrave.jibs.8400202

Lazarus, R. S., \& Folkman, S. (1984). Stress, Appraisal and the Coping Process. New York: Springer.

Lian, H., Ferris, D. L., \& Brown, D. J. (2012). Does Power Distance Exacerbate or Mitigate the Effects of Abusive Supervision? It Depends on the Outcome. Journal of Applied Psychology, 97, 107-123. https://doi.org/10.1037/a0024610

Lin, W., Wang, L., \& Chen, S. (2013). Abusive Supervision and Employee Well-Being: The Moderating Effect of Power Distance Orientation. Applied Psychology, 62, 308-329. https://doi.org/10.1111/j.1464-0597.2012.00520.x

Nanus, B. (1992). Visionary Leadership: Creating a Compelling Sense of Direction for Your Organization. Journal of Academic Librarianship, 20, 237.

O'Neill, P., \& Sevastos, P. (2013). The Development and Validation of a New Multidimensional Job Insecurity Measure (JIM): An Inductive Methodology. Journal of Occupational Health Psychology, 18, 338-349. https://doi.org/10.1037/a0033114

Tepper, B. J. (2000). Consequences of Abusive Supervision. Academy of Management Journal, 43, 178-190.

Tepper, B. J. (2007). Abusive Supervision in Work Organizations: Review, Synthesis, and Research Agenda. Journal of Management: Official Journal of the Southern Management Association, 33, 261-289. https://doi.org/10.1177/0149206307300812 